\title{
COMMENTARY
}

\section{Therapeutic hypothermia post out-of-hospital cardiac arrest - more questions than answers?}

\author{
Richard Lyon* \\ See related research by Haugk et al., http://ccforum.com/content/15/2/R101
}

\begin{abstract}
Nearly a decade since the introduction of therapeutic hypothermia to the ICU for cooling out-of-hospital cardiac arrest patients, key questions remain unanswered: when should cooling be initiated, how rapidly should the patient be cooled and using which device? The Time to Target Temperature study group provides important baseline data on the striking direct relationship between body temperature and survival from out-of-hospital cardiac arrest.
\end{abstract}

Patients post out-of-hospital cardiac arrest (OHCA) are common admissions to the ICU. Therapeutic hypothermia has been shown to improve both survival and neurological outcome for OHCA patients surviving to reach the ICU and now forms part of routine postresuscitation care. The Time to Target Temperature (TTTT) study group presents key observations on the relationship between body temperature and outcome following OHCA [1], yet ultimately are we left with more questions than answers on therapeutic hypothermia?

Nearly a decade ago two landmark papers fundamentally changed the practice of post-resuscitation care. The Hypothermia after Cardiac Arrest study group [2] and Bernard and colleagues [3] not only demonstrated the benefit of cooling OHCA patients but also highlighted how hugely effective the therapy was, with a number needed to treat of seven patients and six patients, respectively, for survival. Such impressive therapeutic benefit is rarely seen in medical practice, let alone in critical care medicine. A key difference between these two studies was the time from return of spontaneous circulation (ROSC) to the onset of cooling. The time to reach the target temperature $\left(<34^{\circ} \mathrm{C}\right)$ varied greatly from

*Correspondence: richardlyon@doctors.org.uk

Emergency Department, Royal Infirmary of Edinburgh, Little France Crescent, Edinburgh EH16 4SA, UK immediately post ROSC to over 16 hours post ROSC and yet the therapeutic benefit of cooling was still evident. The TTTT group demonstrated that the change in body temperature during the period from ROSC to cooling initiation has a direct relationship on survival [1].

Since 2002 few studies have examined the optimum method, rate of cooling and timing of initiation. Little is known about the mechanism of action of therapeutic hypothermia. Whilst animal evidence strongly suggests that early cooling, especially intra-arrest, is beneficial, few human studies have demonstrated a benefit from early cooling. Early cooling, in the prehospital or emergency department setting, has significant technical challenges and may distract from the basic principles of resuscitation. Yet emerging evidence suggests that cold reperfusion at the time of ROSC may confer greater benefit in limiting ischaemic-reperfusion injury. For cold reperfusion to occur, very rapid intra-arrest cooling would be required and some novel intranasal cooling devices have shown promising initial results [4]. Previous studies have demonstrated that most OHCA patients are relatively hypothermic in the prehospital phase, and whether initiating cooling, maintaining hypothermia or even normothermia would confer survival benefit remains unknown [5]. Although OHCA patients are naturally hypothermic in the immediate phase following collapse, they may still benefit from early therapeutic cooling.

The TTTT group elegantly demonstrate that OHCA patients destined for a favourable outcome re-warm rapidly post $\mathrm{OHCA}$, are warmer at cooling initiation and take longer to reach the target therapeutic temperature than OHCA patients destined for an unfavourable outcome. This observation appears contradictory to the notion that earlier, faster cooling favours a positive outcome post OHCA. No definitive explanation can yet be offered for the TTTT group finding. Unfavourable OHCA patients would appear to lack the homeostatic mechanism to regulate body temperature and appear to cool faster than favourable patients. Underlying mechanisms are postulated to include ischaemic hypothalamic damage and the inability of hypoxic mitochondria to generate heat. 
Clearly, the underlying cardiovascular and neurological processes involved with regulating body temperature post OHCA need further research and explanation. A better understanding of the mechanisms through which therapeutic hypothermia confers neuroprotection and survival would allow the therapy to be optimised, potentially saving many more lives. Despite nearly a decade of research since the routine introduction of therapeutic hypothermia to the ICU, a key question remains: what is the optimum time point to initiate therapeutic hypothermia post $\mathrm{OHCA}$ ?

Further prospective trials are urgently required to provide answers to the key questions surrounding cooling post OHCA, particularly to determine the optimum means, timing and rate of cooling. The TTTT group study provides a platform with important baseline data for planning this vital future research.

Abbreviations

ICU, intensive care unit; OHCA, out-of-hospital cardiac arrest; ROSC, return of spontaneous circulation; TTTT, Time to Target Temperature.

\section{Competing interests}

The author declares that he has no competing interests.

\section{Acknowledgements}

RL has been supported by a Chest, Heart and Stroke Scotland Fellowship Grant. No funding was received for the present commentary.
Published: 15 April 2011

\section{References}

1. Haugk M, Testori C, Sterz F, Uranitsch M, Holzer M, Behringer W, Herkner H; Time To Target Temperature Study Group: Relationship between time to target temperature and outcome in patients treated with therapeutic hypothermia after cardiac arrest. Crit Care 2011, 15:R101.

2. Hypothermia after Cardiac Arrest Study Group: Mild therapeutic hypothermia to improve the neurologic outcome after cardiac arrest. N Engl J Med 2002, 346:549-556.

3. Bernard SA, Gray TW, Buist MD, Jones BM, Silvester W, Gutteridge G, Smith K: Treatment of comatose survivors of out-of-hospital cardiac arrest with induced hypothermia. N Engl J Med 2002, 346:557-563.

4. Castrén M, Nordberg P, Svensson L, Taccone F, Vincent JL, Desruelles D, Eichwede F, Mols P, Schwab T, Vergnion M, Storm C, Pesenti A, Pachl J, Guérisse F, Elste T, Roessler M, Fritz H, Durnez P, Busch HJ, Inderbitzen B, Barbut D: Intra-arrest transnasal evaporative cooling: a randomized, prehospital, multicenter study (PRINCE: Pre-ROSC IntraNasal Cooling Effectiveness). Circulation 2010, 122:729-736.

5. Lyon RM, Richardson SE, Hay AW, Andrews PJ, Robertson CE, Clegg GR: Esophageal temperature after out-of-hospital cardiac arrest: an observational study. Resuscitation 2010, 81:867-871.

doi:10.1186/cc10123

Cite this article as: Lyon R: Therapeutic hypothermia post out-of-hospital cardiac arrest - more questions than answers? Critical Care 2011, 15:151. 